\section{Results of the Belgian Sentinel Network of general practitioners on the involvement of therapists in stroke rehabilitation}

Silke Francois, ${ }^{1}$ Viviane Van Casteren, ${ }^{2}$ Katrien Vanthomme, 2 Liesbeth Borgermans, ${ }^{1}$ Dirk Devroey'

1Department of Family Medicine and Chronic Care, University of Brussels; 2Department of Public Health and Surveillance, Scientific Institute of Public Health, Brussels, Belgium

\begin{abstract}
This study examines which therapists are involved in the rehabilitation of stroke survivors in Belgium at different points in time. A nationwide registration of stroke patients was provided by 199 and 189 family physicians working in sentinel practices for the years 2009 and 2010 respectively. 326 patients who were diagnosed with stroke were included. Patients with paralysis/paresis received significant more physiotherapy after one month (63\%) compared to non-paralysed patients (38\%) $(\mathrm{P}=0.005)$. Residing in a nursing home was associated with higher proportions of patients receiving physiotherapy, both after one $(\mathrm{P}=0.003)$ and $\operatorname{six}(\mathrm{P}=0.002)$ months. $31 \%$ of patients with aphasia were treated by a speech and language therapist after one month, which decreased after six months to 20\%. After six months, the patients in a nursing home received significant more often speech and language therapy $(\mathrm{P}=0.004)$, compared to patients living at home. The proportion of patients receiving stroke rehabilitation services provided by physiotherapists, speech/language therapists and occupational therapists is rather low, especially 6 months after the critical event.
\end{abstract}

\section{Introduction}

Stroke is a major health problem worldwide in terms of morbidity and mortality. 1 Symptoms in stroke patients vary from temporary deficits to long-term persisting physical and cognitive impairments. The effectiveness of both stroke unit care in nursing homes and primary care interdisciplinary teams in reducing mortality, institutionalization, and dependence has been established. ${ }^{2-6}$ It remains how- ever unclear which therapists should ideally be involved at different moments in time for different types of patients with stroke. ${ }^{7-12}$

In Belgium, the family physician (FP) has the responsibility for managing and coordinating the long-term care of stroke survivors. ${ }^{2}$ Other professional disciplines that are involved in stroke rehabilitation are physiotherapists, speech and language therapists (SLT) and occupational therapists (OT).

In this study we want to examine which therapists are involved in the rehabilitation of Belgian stroke survivors at different points in time and to what extent the setting in which the patient resides is of influence on the provision of support provided by therapists.

\section{Materials and Methods}

\section{Belgian Network of Sentinel General Practitioners}

A nationwide observational registration was made by Belgian FP's participating in the sentinel practices. Those FP's are, with respect to age and gender, representative of FP's in Belgium. In 2009, 199 FP's from 156 sentinel practices participated in this study. In 2010, 189 FP's, working in 141 sentinel practices, were involved in this study. During this study, the sentinel practices reached $1.8 \%$ and $1.5 \%$ of the Belgian population, respectively in 2009 and 2010. This Belgian network of sentinel practices has been functioning since 1979 and is a dependable source on the surveillance of morbidity in Belgium. ${ }^{13-15}$ By means of a cluster analysis, based on epidemiological criteria, the sentinel practices are distributed evenly over the Belgian territory. 14,15

\section{Case ascertainment}

FPs from the Sentinel Network recorded all cerebrovascular events for the years 2009 and 2010 i.e. transient ischemic attack (TIA) and stroke. Stroke was defined using the WHO definition as rapidly developing signs of neurological deficits as a result of vascular pathology (thrombosis, embolism or haemorrhage) with symptoms lasting at least $24 \mathrm{~h}$, or leading to death. 16 TIA was defined as a neurological deficit lasting less than 24h, typically minutes rather than hours. ${ }^{16}$ All events, including those for which there was no preceding contact with the FP, were recorded. No exclusion criteria were applied with regard to age or co-morbidity.

\section{Ethical approval}

Ethical approval for registration by the Belgian Network of Sentinel General Practices was obtained by the ethical committee of the Scientific Association of Flemish Family Physicians. Patients were informed about the
Correspondence: Dirk Devroey, University of Brussels, Department of Family Medicine and Chronic Care, Laarbeeklaan 103, B-1090 Brussels, Belgium.

Tel.: +32.2.477.43.11 - Fax: +32 2 477.43.01.

E-mail: dirk.devroey@vub.ac.be

Key words: Stroke; primary care; rehabilitation; physiotherapy; speech and language therapy.

Acknowledgements: the authors thank all participating physicians from the sentinel network for completing the surveys.

Contributions: SF, analysis and interpretation of data, drafting of the manuscript, critical revising and final approval of the version submitted; VVC, conception, design, interpretation of data, critical revising and final approval of the version submitted; KV, conception, design, interpretation of data, critical revising and final approval of the version submitted; LB, interpretation of data, drafting of the manuscript, critical revising and final approval of the version submitted; DD, conception, design, analysis and interpretation of data, drafting of the manuscript and final approval of the version submitted.

Conflict of interest: the authors declare no potential conflict of interest.

Received for publication: 3 December 2016. Revision received: 4 December 2016.

Accepted for publication: 7 December 2016.

This work is licensed under a Creative Commons Attribution NonCommercial 4.0 License (CC BYNC 4.0).

CC Copyright S. Francois et al., 2016 Licensee PAGEPress, Italy

Neurology International 2016; 8:5846 doi:10.4081/ni.2016.5846

registration by means of a poster in the waiting room. The poster was displayed on a good, visible location and informed about the diseases which were registered, the transmitted information and the possibility to decline participation. Patients could decline their participation at any time by a simple request to their physician. In the case of the sentinel practices the informed consent is a silent and passive consent. However, the patients can decide at any moment that their information should not be used for the registration. They can decide this before the consultation or at any moment after the consultation. This procedure was approved by the ethical committee, the national board of physicians, and the national privacy commission.

The key statements of the poster in the waiting room inform about i) the diseases which are registered at that moment (for example stroke, Lyme, cancers, etc), ii) the parameters 
which are registered: year of birth and gender but no names (the patients can consult a registration form), iii) the possibility to decline participation, iv) the approval of the method by the committee for medical ethics and the privacy commission.

The participating physicians are asked to display the poster at a visible place. This is not controlled by any organisation but all participating physicians confirm the visibility of the poster as part of the yearly application to the network.

Patients who cannot express their oral or written opposition to participate in the registration can do this - according to the Belgian law on patient rights - by means of a proxy that defends the interests of the patient.

\section{Data collection and statistical analysis}

Age, sex, medical history, date and duration of the event were registered by their family physician by means of a questionnaire one week after the event occurred. Also the impairments caused by the event, the living situation at the moment of the event and the patient's condition after 24 hours were registered. One and six months after the event occurred, FPs were asked to fill in a questionnaire including outcomes of the stroke (disability and mortality), the current living situation of the patient and the provision of support by therapists.

Data were stored at the Scientific Institute of Public Health. Several control measures ensured the quality of the data. IBM SPSS Statistics 20 was used for analysis and statistical processing. Cross-tables were used to detect differences between groups by means of chi-square tests. Fisher's exact test was used when less than ten observations were obtained. Student t-test was used to compare the mean age between men and women. Multivariate analyses were performed with backward conditional logistic regression. The independent variables for all logistic regressions were age (10 years age-groups), sex, whether or not suffering from a neurological deficit (paralysis/paresis, aphasia, dysphagia, incontinence) and living situation (home or nursing home). Logistic regression performed for the place of residence (home or nursing home) also included hypertension, diabetes mellitus and originally place of residence at the moment of the event (home or nursing home) as independent variables.

\section{Results}

\section{Information on patients}

A total of 664 patients were registered of which 326 patients (144 men and 182 women) received a final diagnosis for stroke. The other patients in the survey had suffered from TIA $(n=202)$ or other diseases including acute subdural hematoma and epileptic crisis, amongst others. Analysis in this study is based on 326 patients who were diagnosed with stroke. Mean age in woman was 77 years (SD $13 y$ ), compared to 73 years in men (SD 12y) $(\mathrm{P}=0.005)$.

Eighty-one percent of the stroke patients were paralysed or had paresis, $77 \%$ had aphasia, $31 \%$ showed swallowing problems and $22 \%$ suffered from incontinence.

\section{Physiotherapy}

Table 1 shows a significant higher proportion of patients receiving physiotherapy in the paralysed group after one month (63\%) compared to $38 \%$ in the non-paralysed survivors $(\mathrm{P}=0.005)$. After six months, the non-paral- ysed patient group remained approximately at the same level in terms of physiotherapy (39\%) whilst the affected paralysed patient group showed a significant decrease in treatment provided by the physiotherapist (50\%) $(\mathrm{P}=0.021)$. At six months, this difference was no longer significant $(\mathrm{P}=0.256)$ (Table 2).

Patients who presented with dysphagia were provided significant more physiotherapy compared to patients who had no dysphagia after one month $(\mathrm{P}=0.002)$ (Table 1). After six months, this difference disappeared $(\mathrm{P}=0.325)$ (Table 2). In patients with incontinence a significant higher proportion of patients received treatment by a physiotherapist compared to patients without incontinence $(\mathrm{P}=0.003$ and $\mathrm{P}=0.007$ respectively after one and six months) (Tables 1 and 2).

The presence of aphasia was of no influence in whether or not receiving physiotherapy.

Table 1. Follow-up one month after the event and according to the neurological deficit in $\%(\mathbf{n} / \mathrm{N})$.

\begin{tabular}{lccc} 
& With ... & Without ... & P-value \\
...paralysis/paresis & & & \\
Physiotherapist & $63(100 / 158)$ & $38(14 / 37)$ & 0.005 \\
Speech language therapist & $27(31 / 116)$ & $16(5 / 32)$ & 0.286 \\
Occupational therapist & $16(18 / 115)$ & $3(1 / 29)$ & 0.134 \\
...speech problems & & & \\
Physiotherapist & $61(87 / 142)$ & $52(29 / 56)$ & 0.223 \\
Speech language therapist & $31(32 / 102)$ & $9(4 / 46)$ & 0.004 \\
Occupational therapist & $14(14 / 97)$ & $9(4 / 47)$ & 0.468 \\
\hline ...swallowing problems & & & \\
Physiotherapist & $78(38 / 49)$ & $53(77 / 146)$ & 0.002 \\
Speech language therapist & $32(10 / 31)$ & $22(25 / 116)$ & 0.214 \\
Occupational therapist & $19(6 / 31)$ & $12(13 / 112)$ & 0.401 \\
...incontinence & & & \\
Physiotherapist & $85(23 / 27)$ & $54(91 / 167)$ & 0.003 \\
Speech language therapist & $12.5(2 / 16)$ & $25(33 / 131)$ & 0.426 \\
Occupational therapist & $19(3 / 16)$ & $13(16 / 128)$ & 0.709 \\
\hline
\end{tabular}

Table 2. Follow-up 6 months after the event and according to the neurological deficit in $\%(n / N)$.

\begin{tabular}{|c|c|c|c|}
\hline & With ... & Without ... & P-value \\
\hline $\begin{array}{l}\text {...paralysis/paresis } \\
\text { Physiotherapist } \\
\text { Speech language therapist } \\
\text { Occupational therapist }\end{array}$ & $\begin{array}{l}50(69 / 138) \\
18(19 / 108) \\
13(14 / 106)\end{array}$ & $\begin{array}{c}39(12 / 31) \\
8(2 / 26) \\
4(1 / 25)\end{array}$ & $\begin{array}{l}0.256 \\
0.347 \\
0.345\end{array}$ \\
\hline $\begin{array}{l}\text {...speech problems } \\
\text { Physiotherapist } \\
\text { Speech language therapist } \\
\text { Occupational therapist }\end{array}$ & $\begin{array}{l}50(60 / 121) \\
20(19 / 95) \\
15(14 / 92)\end{array}$ & $\begin{array}{c}44(22 / 50) \\
5(2 / 40) \\
0(0 / 40)\end{array}$ & $\begin{array}{l}0.510 \\
0.041 \\
0.009\end{array}$ \\
\hline $\begin{array}{l}\text {...swallowing problems } \\
\text { Physiotherapist } \\
\text { Speech language therapist } \\
\text { Occupational therapist }\end{array}$ & $\begin{array}{l}55(22 / 40) \\
29(9 / 31) \\
28(9 / 32)\end{array}$ & $\begin{array}{l}46(59 / 128) \\
10(10 / 100) \\
5(5 / 96)\end{array}$ & $\begin{array}{l}0.325 \\
0.026 \\
0.002\end{array}$ \\
\hline $\begin{array}{l}\text {...incontinence } \\
\text { Physiotherapist } \\
\text { Speech language therapist } \\
\text { Occupational therapist }\end{array}$ & $\begin{array}{c}79(15 / 19) \\
25(3 / 12) \\
40(6 / 15)\end{array}$ & $\begin{array}{c}44(65 / 148) \\
14(17 / 120) \\
7(8 / 114)\end{array}$ & $\begin{array}{l}0.007 \\
0.529 \\
0.003\end{array}$ \\
\hline
\end{tabular}


Stroke survivors residing in a nursing home received significantly more often physiotherapy compared to patients living at home. After one month $52 \%$ of the patients living at home received physiotherapy in contrast to $81 \%$ of the people living in a nursing home $(\mathrm{P}=0.003)$. After six months, these proportions decrease to respectively $41 \%$ and $76 \%(\mathrm{P}=0.002)$. If we considered patients with paralysis/paresis only, differences in physiotherapy at home or in a nursing home were comparable. After one month, $57 \%$ of these patients living at home received treatment from a physiotherapist, compared to $83 \%$ in a nursing home $(\mathrm{P}=0.013)$. After six months, $44 \%$ of patients living with paresis/paralysis at home were treated by a physiotherapist in contrast to $75 \%$ of the patients residing in a nursing home $(\mathrm{P}=0.018)$. Multivariate analysis showed that, after one month, being of female sex, suffering from paralysis/paresis, dysphagia or incontinence were of significant importance to the likelihood of being treated by a physiotherapist. After six months, multivariate analysis showed no influence of the presence of a neurological deficit, but being of female sex and being older increased the likelihood of getting physiotherapy (Tables 3 and 4).

\section{Speech and language therapy}

One month after the event, $23 \%$ of the patients received SLT at home. In a nursing home this percentage was $16 \%(\mathrm{P}=0.721)$. After six months, the difference in place of residence became significant: $11 \%$ patients at home received SLT compared to $33 \%$ in a nursing home $(\mathrm{P}=0.004)$.

If patients with speech problems were considered only, no significant difference in the amount of patients receiving SLT at home or in a nursing home after one month could be identified (32\% at home, 19\% in a nursing home; $\mathrm{P}=0.480$ ). After six months, the difference in proportions of patients receiving SLT at home or in a nursing home for those patients with aphasia became significant (14\% at home, $38 \%$ in a nursing home; $\mathrm{P}=0.030$ ).

Stroke survivors with aphasia received significantly more SLT compared to patients without speech difficulties, both after one $(\mathrm{P}=0.004)$ and six months $(\mathrm{P}=0.041)$ (Tables 1 and 2). Among the patients with swallowing problems higher proportions of patients receiving SLT were observed after six months compared to patients without swallowing problems $(\mathrm{P}=0.026)$ (Table 2). Multivariate analysis with SLT as dependent variable after one month showed that younger age and having speech problems increased the likelihood of receiving SLT. After six months, patients with aphasia were more likely to receive SLT (Tables 3 and 4).

Table 3. Multivariate analyses after one month.

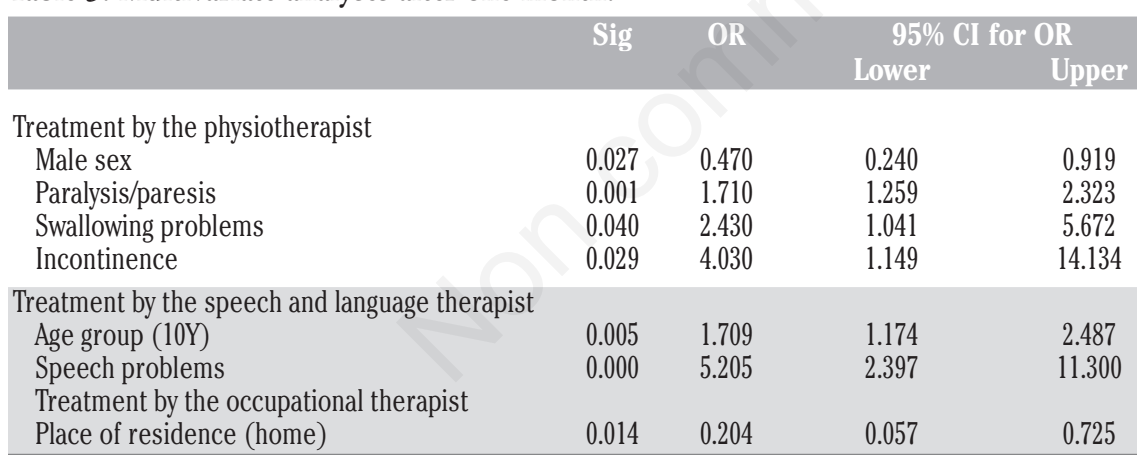

Variables in the model: Age group (10Y), sex, paralysis/paresis (yes/no), speech problems, swallowing problems (yes/no), incontinence (yes/no), place of residence (home or nursing home).

Table 4. Multivariate analyses after 6 months.

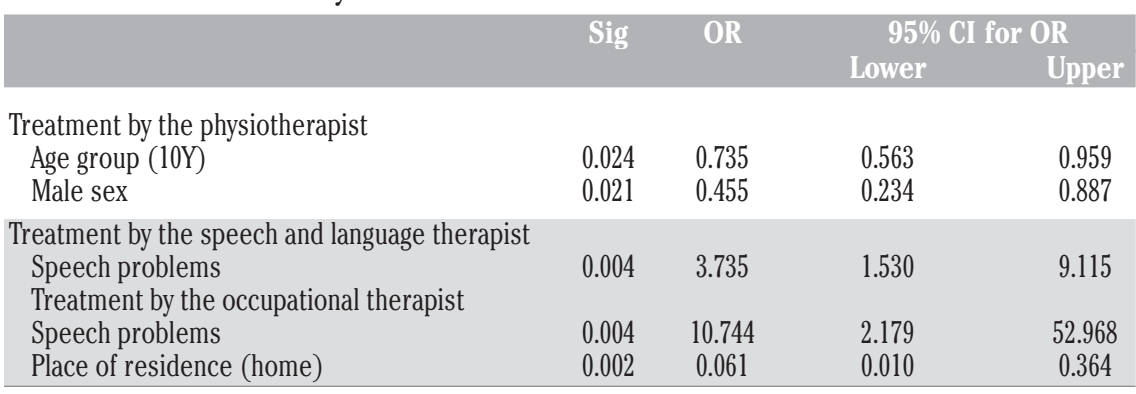

Variables in the model: Age group (10Y), sex, paralysis/paresis (yes/no), speech problems, swallowing problems (yes/no), incontinence

(yes/no), place of residence (home or nursing home).

\section{Occupational therapy}

Six and four percent of patients residing at home (alone, with partner or with parents/children) were treated by an OT after one and six months, respectively. Twenty-nine percent and $47 \%$ of patients who stayed in a nursing home were treated by an $0 \mathrm{~T}$ after one and six months, respectively $(\mathrm{P}=0.01$ and $\mathrm{P}<0.001)$.

After one month, there was no influence of one of the four major neurological deficits in getting support by an OT. However, after six months, a significant higher proportion of patients received OT in the case of either speech, swallowing problems or incontinence compared to patients who did not present these problems (Tables 1 and 2).

After one month, multivariate analysis showed that patients residing in a nursing home were more likely of getting support by an OT, compared to the patients who lived at home. After six months patients who resided in a nursing home and who had speech problems showed a greater likelihood for treatment by an 0T (Tables 3 and 4).

\section{Discussion}

Data of this study show that overall a low proportion of patients with stroke receive treatments by physiotherapists, speech/language and occupational therapists compared to what is considered a good practice for these patients. ${ }^{2-6}$ The proportion of patients with paralysis/paresis treated by a physiotherapist remained rather low after one month and even dropped further down after six months. Previous studies have documented on a far larger amount of patients receiving support by physiotherapists after six months in their home setting compared to the numbers we documented in our study. The low rates of patients receiving physiotherapy contrasts with evidence recommending to continue physiotherapeutic support during the entire rehabilitation process. ${ }^{3,4}$ The proportion of patients receiving SLT in the case of severe aphasia and dysphagia was also particularly low. A recent review of randomised controlled trials showed multiple advantages for patients with aphasia receiving SLT compared to patients not receiving the service,,$^{5}$ and especially a positive effect when treatment is initiated within the first three months. ${ }^{6}$ Dysphagia is shown to be a potential risk for aspiration pneumonia and suffocation, risk of dehydration and malnutrition, and depriving enjoyable activity. 17

Possible reasons for the differences found in the number of patients who received physiotherapy SLT and OT according to their living situation may be related to the structural presence and easy access of physiotherapists, SLT 
and OT in nursing homes, whereas in primary care access to physiotherapists, STL and OT, especially to those providing home visits, is more difficult. Interdisciplinary stroke teams in primary care that operate as professional teams in support of the FP are not available in Belgium, which complicates the co-ordinating role of the FP. Another reason for the differences found may be related to elevated out-ofpocket expenses for patients in primary care and the absence of reimbursement of particular providers such as the OT. There is however evidence showing that physiotherapy provided at home is as beneficial as physiotherapy provided in institutions. ${ }^{18,19}$

Research has also shown that domiciliary occupational therapy for six weeks starting immediately after hospital discharge is beneficial at eight weeks compared to routine followup. ${ }^{20}$

\section{Limitations to the study}

Limitations to this study are three-fold. First, the interventions provided by the aforementioned therapists were not operationalized in terms of type and intensity. FP's had to register on the presence of a particular therapist only at different moments in time. Second, no data were recorded on conditions that may have interfered with the effectiveness of rehabilitation, such as cardiopulmonary disease, pre-existing conditions including osteoarthritis, pain and others. Such disorders may limit exercise tolerance as well as the number and duration of treatments by therapists.

Third, the neurological deficit was questioned only once at the start of the study. It was not repeated after six months, although it seems logic to assume that the neurological damage presented in patients evolved over time. This may explain some of the results, although in part.

\section{Conclusions}

A low proportion of patients received treatments by physiotherapists, speech/language and occupational therapists compared to what is considered a good practice for stroke rehabilitation. Patients residing at home received, for similar disabilities, less rehabilitation services compared to patients residing in nursing homes. Important clinical and policy lessons can be drawn from this study in terms of the need for increased compliance to good practices on stroke rehabilitation and affordable access for patients to interdisciplinary stroke teams in primary care in support of the FP.

\section{References}

1. Mathers C, Bernard C, Iburg K, et al. World Health Organization: Estimated proportional mortality (\%). 2004. Available from: https://apps.who.int/infobase/Mortality.asp $\mathrm{x}$

2. U.S. Department of Health And Human Services Public Health Service. National Institutes of Health. Post-stroke rehabilitation. 2011. Available from: http:/www.ninds.nih.gov/disorders/stroke/ poststrokerehab.htm

3. Gordon NF, Gulanick M, Costa F, et al. Physical activity and exercise recommendations for stroke survivors: an American Heart Association scientific statement from the council on clinical cardiology, subcommittee on exercise, cardiac rehabilitation, and prevention; the Council on Cardiovascular Nursing; the Council on Nutrition, Physical Activity, and Metabolism; and the Stroke Council. Circulation 2004;109:2031-41.

4. Bruce H, Dobkin MD. Rehabilitation after Stroke. N Engl J Med 2005;352:1677-84.

5. Kelly H, Brady MC, Enderby P. Speech and language therapy for aphasia following stroke (review). Cochrane Library 2010;7:1-176.

6. Robey, Randal R. A meta-analysis of clinical outcomes in the treatment of aphasia. J Speech Lang Hear Res 1998;41:172-87.

7. Bhogal SK, Teasell R, Speechley M. Intensity of aphasia therapy, impact on recovery. Stroke 2003;34:987-93.

8. Marshall, RC. The impact of intensity of aphasia therapy on recovery. Stroke 2008;39:e48.

9. Bakheit AM, Shaw S, Barrett L, et al. A Prospective, randomized, parallel group, controlled study of the effect of intensity of speech and language therapy on early recovery from poststroke aphasia. Clin
Rehabil 2007;21:885-94

10. Teasell R, Foley N, Bhogal S, Speechley M. The elements of stroke rehabilitation stroke 2011. July. Available from: http://www.ebrsr.com/reviews_details.php? 34

11. Steultjens E, Dekker J, Bouter ML, et al. Occupational therapy for stroke patients: a systematic review. Stroke 2003;34:676-87.

12. Legg L, Langhorne P. Rehabilitation therapy services for stroke patients living at home: systematic review of randomized trials. Lancet 2004;363:352-56.

13. Devroey D, Van Casteren V, Buntinx F. Registration of stroke through the Belgian sentinel network and factors influencing stroke mortality. Cerebrovasc Dis 2003;16:272-79.

14. Stroobant A, Van Casteren V, Thiers G. Surveillance systems from primary-care data: surveillance through a network of sentinel general practitioners. In: Eylenbosch WJ, Noah N, eds. Surveillance in health and disease. Oxford: Oxford University Press, 1988. pp 62-74.

15. Lobet MP, Stroobant A, Mertens R, et al. Tool of validation of the network of sentinel general practitioners in the Belgian health care system. Int $\mathrm{J}$ Epidemiol 1987;16:612-8.

16. Hatano S. Experience from a multicentre stroke register: a preliminary report. Bull World Health Organ 1976;54:541-53.

17. Putman K, De Wit L, Schupp W, et al. Variations in service delivery at home after inpatient stroke rehabilitation: a multicentre study. J Rehabil Med 2009;41:646-53.

18. Young JB, Forster A. The Bradford community stroke trial: results at six months. BMJ 1992;304:1085-9.

19. Holmqvist L, Von Koch L, Kostulas V, et al. A randomized controlled trial of rehabilitation at home after stroke in Southwest Stockholm. Stroke 1998;29:591-7.

20. Gilbertson L, Langhorne P, Walker A, et al. Domiciliary occupation therapy for patients with stroke discharged from hospital: randomized controlled trial. BMJ 2000;320:603-6. 